\title{
EVOLUÇÃO BIOMOLECULAR HOMOQUIRAL. A ORIGEM E A AMPLIFICAÇÃO DA QUIRALIDADE NAS MOLÉCULAS DA VIDA
}

\author{
José Augusto R. Rodrigues \\ Instituto de Química, Universidade de Campinas, CP 6154, 13093-971 Campinas - SP, Brasil
}

Recebido em 22/10/09; aceito em 22/12/09; publicado na web em 6/5/10

\begin{abstract}
HOMOCHIRAL BIOMOLECULAR EVOLUTION. THE ORIGIN AND THE AMPLIFICATION OF CHIRALITY IN LIFE MOLECULES. The fact that biologically relevant molecules exist only as one of the two enantiomers is a fascinating example of complete symmetry breaking of chirality and has long intrigued our curiosity. The origin of this selective chirality has remained a fundamental enigma with regard to the origin of life since the time of Pasteur, 160 years ago. The symmetry breaking processes, which include autocatalytic crystallization, asymmetric autocatalysis, spontaneous crystallization, adsorption and polymerization of amino acids on mineral surfaces, provide new insights into the origin of biomolecular homochirality.
\end{abstract}

Keywords: origin of life; handedness; symmetry breaking.

\section{INTRODUÇÃO}

A quiralidade molecular é um fenômeno que pervaga na natureza e tem fascinado químicos e físicos desde sua descoberta em meados do século XIX. Um aspecto especialmente contundente é a homoquiralidade da vida. As macrobiomoléculas tendem a ser homoquirais o que implica serem construídas a partir de unidades de mesma quiralidade. Entre os eucariotos, todos os aminoácidos proteinogênicos possuem a configuração L, enquanto que seu enantiômero D é necessário para formar as paredes das células das bactérias. Várias hipóteses foram enunciadas para explicar como a natureza introduziu tal viés favorecendo um enantiômero preferencialmente sobre o outro. A intuição de Pasteur sobre a "dissimetria das forças cósmicas"1 encontrou sua comprovação no conceito mais moderno de violação da paridade, ${ }^{2}$ que resulta na sutil diferença de energia entre dois enantiômeros. Esta diferença tem sido assunto de numerosos cálculos teóricos, ${ }^{3}$ cuja comprovação experimental ainda litigiosa é motivo de intensa discussão sobre se esse efeito tem responsabilidade sobre a origem da homoquiralidade da vida. Muito embora a origem desta assimetria permaneça desconhecida, ela é frequentemente questionada se vida poderia existir ou ser originada sem a quiralidade molecular. A origem da homoquiralidade é intrínseca à origem da vida. Se quisermos entender como a vida surgiu na Terra (ou possivelmente em outro lugar) devemos compreender como a homoquiralidade emergiu a partir dos blocos quirais de construção (enantiômeros). ${ }^{4}$

A resolução de racematos é comumente realizada através de reagentes ou catalisadores quirais, enquanto é uma prática rara a resolução espontânea de enantiômeros por cristalização, ou pela cristalização de moléculas aquirais em grupos espaciais quirais. Os numerosos exemplos descritos, em geral resultam de experimentos serendipiticos em lugar dos oriundos de um planejamento prévio. Em meados do século XIX, Pasteur resolveu um aparente paradoxo de que sais de amônio e sódio do ácido (+)-tartárico ativo e do ácido racêmico inativo, também chamado de ácido paratartárico, pareciam serem isomorfos e idênticos em todos os aspectos salvo a atividade ótica. Repetindo a cristalização do sal racêmico inativo em temperaturas abaixo de $28^{\circ} \mathrm{C}$, Pasteur ${ }^{5}$ obteve dois grupos de cristais hemiédricos, relacionados morfologicamente com as formas imagem-especular e objeto que não se sobrepõem, semelhante aos dois grupos de cristais de quartzo.

e-mail: jaugusto@iqm.unicamp.br
Um grupo provou ser isomorfo com os cristais do correspondente (+)-tartarato natural e ter em solução uma rotação ótica específica com sinal positivo. O outro grupo, com faces cristalinas isomorfas mostrou possuir rotação específica de mesma grandeza, mas com sinal negativo. Pasteur concluiu que as moléculas do ácido (+)- e (-)-tartárico eram estereoquimicamente dissimétricas, relacionadas com as formas de imagem especular que não se sobrepunham, semelhante aos cristais macroscópicos dos sais correspondentes de amônio e sódio. Para realizar resoluções de misturas de enantiômeros sem o uso de reagentes quirais ou de colunas cromatográficas enantiosseletivas (chamada de resolução espontânea), o racemato deve ser um conglomerado (uma mistura mecânica equimolar de cristais que formam um eutético de dois enantiômeros) sob as condições de cristalização. ${ }^{6}$

\section{RESOLUÇÃO INDUZIDA POR CRISTALIZAÇÃO - RESOLUÇÃO ESPONTÂNEA}

É ensinado que um racemato corresponde a quantidades exatamente iguais de enantiômeros. Mas considerando que o número de Avogadro é enorme, do ponto de vista estatístico a chance de haver uma mistura exata 50:50 de dois enantiômeros é muito pequena. ${ }^{7}$ Estas flutuações estatísticas que geram relacionamentos diastereoméricos podem ser exploradas no crescimento de cristais e mesmo havendo um ee $<1 \%$, os cristais do enantiômero em excesso podem induzir aos cristais vizinhos serem do mesmo sinal desse enantiômero em excesso. Esta nucleação primária é a origem de conhecidas resoluções espontâneas, que ocorrerá apenas se o racemato formar um conglomerado no estado sólido. ${ }^{6}$

A quirogênesis, que estuda a origem e a evolução da homogeneidade homoquiral encontrada nos organismos vivos terrestres, tem se tornado um fascinante e controverso enigma da ciência atual. Isto é decorrente da íntima associação entre a busca pela origem da homoquiralidade, e a origem da vida com importantes áreas relacionadas, tais como síntese enantiosseletiva e catálise assimétrica. A quirogênesis deve ter início num ambiente pré-biótico tendo pequenas moléculas e monômeros como substratos. A amplificação a partir do leve desbalanceamento de uma mistura de moléculas quirais (racemato) é orientada pelos princípios básicos da estereoquímica e físico-química, tais como a natureza e as propriedades do estado racêmico, a composição de eutéticos para enantiômeros, e outros relevantes tópicos da termodinâmica e cinética química. ${ }^{8}$ 
Os autores Tamura, Hirotsu e colaboradores realizaram uma resolução por recristalização de um racemato através de uma sequência sucessiva de recristalização preferencial, conforme mostrado na Figura 1. O enriquecimento preferencial foi realizado com uma série de sulfonatos de sulfônio que, através de repetidas recristalizações do racemato, resultou em um enriquecimento alternado dos dois enantiômeros nas águas-mãe e, ao mesmo tempo, os cristais com baixo ee eram recristalizados, tendo os cristais depositados sempre com a quiralidade oposta. ${ }^{9}$ Somente os cristais daqueles sais que se apresentaram como conglomerados foram susceptíveis a esse processo de resolução, enquanto os demais não foram resolvidos por este método.
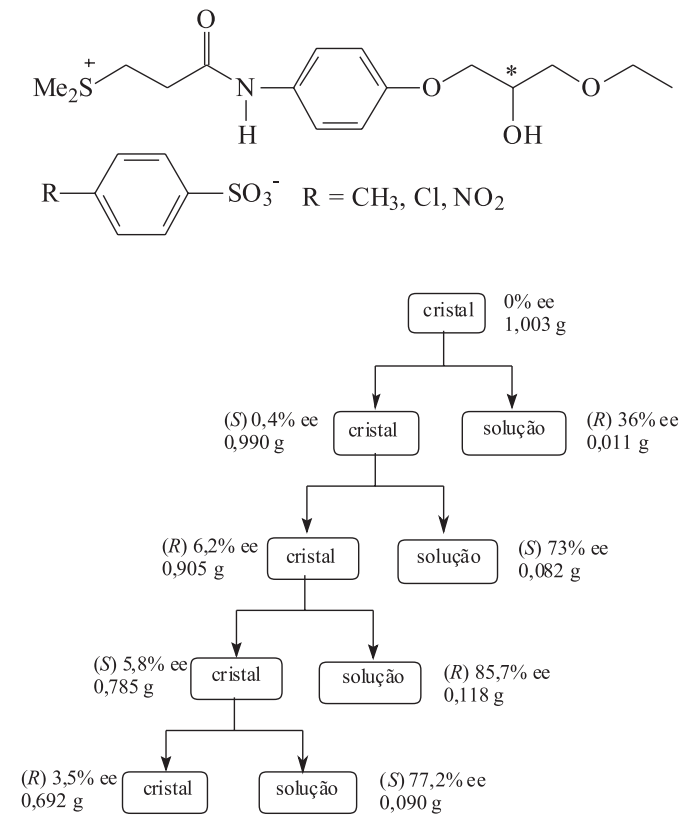

Figura 1. Enriquecimento preferencial por recristalização. Os cristais foram dissolvidos por aquecimento em EtOH. A solução saturada foi resfriada a 25 ${ }^{\circ} \mathrm{C}$, agitada até iniciar a cristalização e, então, deixada em repouso

\section{Autocatálise homoquiral}

Em 1898, Kipping e Pope realizaram a cristalização de $\mathrm{NaClO}_{3}$ a partir de uma solução aquosa saturada, e observaram que os íons aquirais produziram belos cristais com formatos de prismas retangulares no grupo espacial cúbico quiral P2 $3 .{ }^{10}$ Estes cristais de simetria cúbica podem ter facilmente determinada sua quiralidade pela rotação na luz linearmente polarizada $\left(3,6^{\circ} \mathrm{em} 546 \mathrm{~nm}\right)$. Eles mediram a rotação de 3137 cristais de $\mathrm{NaClO}_{3}$ e encontraram que 1571 (50,08\%) eram dextro-rotatórios. Mais recentemente, Kondepudi e colaboradores confirmaram este resultado de Kipping e Pope, mas observaram que quando agitaram (100 rpm) a solução supersaturada, obtiveram a cristalização predominante de apenas um enantiômero. ${ }^{11} \mathrm{O}$ mecanismo sugerido por McBride e Carter é que os cristais começam a nucleação de modo randômico, mas o primeiro cristal ao colidir com o agitador gera clones do mesmo núcleo. ${ }^{12}$ Deve-se enfatizar que a direção da agitação não tem qualquer efeito na quiralidade dos cristais. O processo como um todo é chamado de nucleação secundária (formação de um novo cristal a partir do já existente cristal "mãe") e envolve a formação de novos cristais pela quebra das estruturas dendríticas que são construídas sobre o crescimento do cristal mãe (compare com a nucleação primária que acontece durante resolução espontânea citada anteriormente). O mais notável é que o processo é uma autocatálise quiral, porque estes núcleos cristalinos gerados possuem a mesma quiralidade do cristal mãe. Tanto a velocidade de agitação quanto o tamanho do cristal nucleante são parâmetros críticos na distribuição do excesso enantiomérico. ${ }^{13}$

Aproximadamente quatro décadas atrás, Pincock e colaboradores estudaram a atividade ótica de amostras de 1,1'-binanaftilo cristalizado a $150^{\circ} \mathrm{C}$, e observaram que a distribuição da atividade ótica dos cristais era semelhante a uma curva Gaussiana centrada no zero. ${ }^{14}$ Muito tempo depois, Kondepudi e colaboradores voltaram a estudar essa cristalização realizada agora com uma agitação constante durante o processo de resfriamento de 180 para $150{ }^{\circ} \mathrm{C}$ (o ponto de fusão é $\left.158^{\circ} \mathrm{C}\right) .{ }^{15} \mathrm{~A}$ agitação realizada no fundido super-resfriado a $150{ }^{\circ} \mathrm{C}$, provoca a formação de um grande ee chegando a $77 \%$. A predominância do $(R)-(-)$ ou do $(S)-(+)$ é randômica. Aparentemente, a agitação suprime o lento processo de nucleação primária e, por consequência, favorece a formação de cristais secundários, todos com a mesma homoquiralidade. Durante a agitação, o calor desprendido aumenta levemente a temperatura desfavorecendo a nucleação primária.

$\mathrm{O}$ aspecto chave na geração de assimetria quiral durante a cristalização agitada de uma solução ou fusão é o processo de nucleação secundária. Os mesmos autores, Kondepudi e colaboradores, estudaram o efeito de semear 1,1'-binaftilo fundido com $(R)-(+)$ - ou $(S)-(-)-1,1$ '-bi-2-naftol. O $(R)-(-)-1,1$ '-binaftilo é isomorfo com $(R)$ (+)-1,1'-bi-2-naftol. Desde que 1,1'-bi-2-naftol possui elevado ponto de fusão $\left(208^{\circ} \mathrm{C}\right)$, os autores estudaram a influência da superfície dos cristais de 1,1'-bi-2-naftol na cristalização do 1,1'-binaftilo racêmico. Os experimentos foram assim realizados: 1,1'-binaftilo foi colocado em um tubo de ensaio e aquecido a $180^{\circ} \mathrm{C}$ e agitado por $30 \mathrm{~min}$. Isto assegurou que a amostra inicial de 1,1'-binaftilo fosse racêmica. A amostra foi resfriada a $150{ }^{\circ} \mathrm{C}$ e pequena porção $(10 \%)$ de $(R)-(+)-$ 1,1'-bi-2-naftol ou de (S)-(-)-1,1'-bi-2-naftol foi adicionada a cada tubo de ensaio. Para aumentar sua superfície, o 1,1'-binaftilo foi triturado até formar um pó. A fusão foi continuamente agitada até a total cristalização. O 1,1'-binaftilo cristalizado foi resfriado a temperatura ambiente, dissolvido em benzeno e medida sua rotação ótica específica. Todas as amostras semeadas com $(R)-(+)-1,1$ '-bi-2-naftol ou com $(S)-(-)-1,1$ '-bi-2-naftol apresentaram uma elevada rotação ótica, muito próxima de $100 \%$ ee. Desse modo, foi determinado que o 1,1'-bi-2-naftol é um seletivo agente nucleante quiral para o 1,1'-binaftilo (Figura 2). Assim, o ambiente quiral fornecido por uma fase sólida de um composto quiral pode resultar em uma autocatálise quiral, que gera randomicamente significante ee.

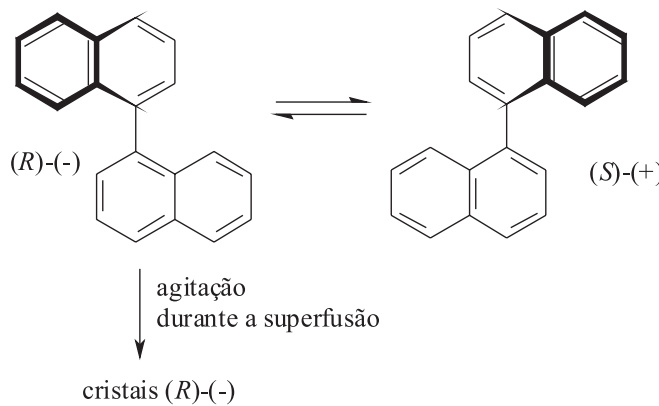

Figura 2. Resolução autocatalítica espontânea quiral

Uma investigação sobre sublimação estereosseletiva levou a compostos enantiomericamente puros a partir de material enantiomericamente enriquecido. Isto foi observado com uma amostra de ácido $(S)$ - $\alpha$-(trifluorometil)lático, que tendo inicialmente $74 \%$ de ee aumentou para $81 \%$ quando armazenado em um tubo fechado, no qual ocorreu uma sublimação parcial. Os autores observaram que a substância sublimada possuía apenas $35 \%$ ee. ${ }^{16}$ Quando a sublimação foi realizada em vaso aberto (pressão ambiente), partindo do derivado de ácido lático com $80 \%$ ee, obtiveram um material não sublimado 
com $99,9 \%$ ee, enquanto que o que sublimou possui um ee inferior (Figura 3).<smiles>CC(O)(C(=O)O)C(F)(F)F</smiles>

(S) $74 \%$ ee tubo selado: $(S) 81 \%$ ee

(S) $80 \%$ ee vasol aberto: $(S) 99,9 \%$ ee

Figura 3. Sublimação do ácido (S)- $\alpha$-(trifluorometil) lático com concomitante aumento do excesso enantiomérico

Os autores demonstraram que as pressões de vapor dos enantiômeros e de suas misturas variam significativamente, e podem depender principalmente da entalpia da decomposição do composto racêmico e da temperatura do processo. As diferenças relevantes nas interações intramoleculares entre enantiômeros e racematos são suficientes para produzir enantiosseparações espontâneas, mesmo sob influências físicas aquirais. Tais diferenças constituem uma manifestação e discriminação estereoisomérica, que constituem um dos maiores desafios da estereoquímica moderna. Este processo de aumento do ee tem a vantagem de ocorrer sem a intervenção de qualquer ação externa ou alguma condição especial do meio, e fornece argumentos para uma reavaliação da geração da homoquiralidade sob as condições prebióticas. ${ }^{17}$ Dados de calores de sublimação, publicados em 1981, já indicavam que interações heteroquirais entre enantiômeros poderiam ser mais fortes ou mais fracas do que as correspondentes interações homoquirais. ${ }^{18}$

Estes protocolos de sublimação não são certamente novos, já que trabalhos anteriores revelaram que sublimação fracionada de algumas substâncias enantiomericamente enriquecidas, incluindo derivados de fenilalanina, forneciam frações de pureza enantioméricas aumentadas. ${ }^{19}$ Certamente é a composição do eutético, com respeito à composição da mistura inicial, que dirige a sublimação preferencial. ${ }^{20}$

\section{Reações assimétricas autocatalíticas}

Em meados do século passado Frank propôs um modelo matemático para a autocatálise quiral, no qual cada enantiômero catalisa sua própria formação e atua como um anticatalisador na produção do enantiômero oposto. ${ }^{21}$ Neste modelo cinético, é possível obter um composto enriquecido enantiomericamente a partir de ee extremamente pequeno, com uma pequena flutuação randômica na mistura racêmica inicialmente formada. Na catálise assimétrica convencional, o catalisador assimétrico produz o produto enantiomericamente enriquecido, cuja estrutura é geralmente diferente daquela do catalisador assimétrico. Em contraste, autocatálise assimétrica é uma automultiplicação de um composto quiral $\mathrm{P}^{*}$, no qual o produto quiral $\mathrm{P}^{*}$ atua como um catalisador quiral $\mathrm{P}^{*}$ para a sua própria produção (Figura 4). A autocatálise implica no crescimento da quantidade do catalisador e, desse modo, vai modificando a razão enantiomérica $R / S$ inicial.

Pesquisadores japoneses, liderados por Kenso Soai, desenvolveram um notável sistema autocatalítico em reações de adição de

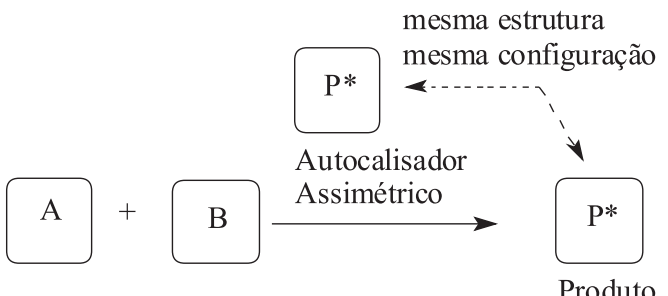

Figura 4. O conceito de autocatálise assimétrica dialquilzincos a aldeídos heteroaromáticos. ${ }^{22}$ Nesta reação, o álcool piridílico de $(R)$-configuração com $86 \%$ ee catalisa sua própria formação, embora com enantiosseleção modesta de 35\% ee, após subtrair a contribuição do catalisador (Figura 5). O (S)-3-piridilalcanol é gerado in situ.

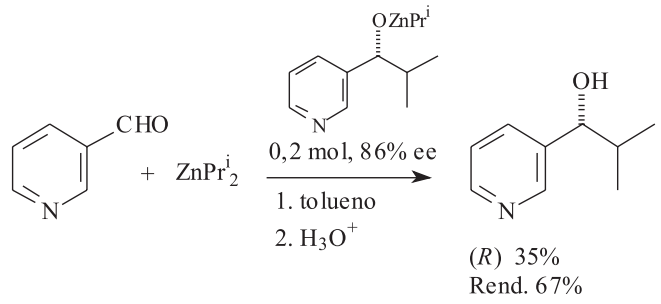

Figura 5. Autocatálise assimétrica na reação de 3-piridilcarbaldeído com organozinco

Nos estudos iniciais de Soai (atualmente é conhecida como reação de Soai) sobre autocatálise, o excesso enantiomérico do produto quiral tinha sempre valor inferior ao catalisador quiral. Entretanto, empregando 3-pirimidilcarbaldeído conseguiu obter pela primeira vez autocatálise assimétrica com amplificação do ee, tendo iniciado com pequeno enantioenriquecimento ( $2 \%$ ee), este foi aumentado significativamente para $88 \%$ ee (Figura 6).

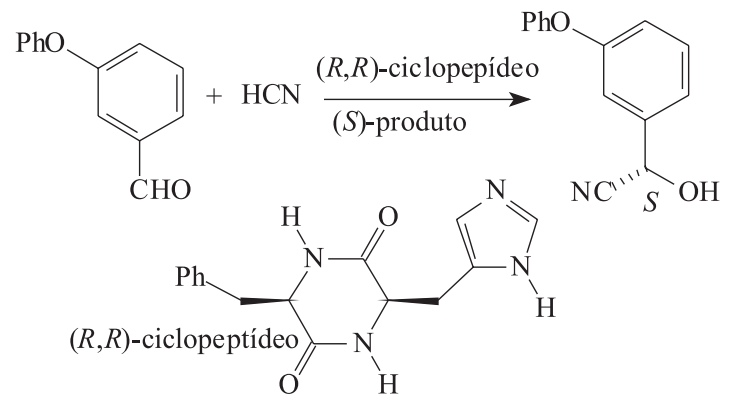

Figura 6. Autocatálise assimétrica com amplificação significativa da quiralidade de 2 para $88 \%$ ee

Quando o (S)-pirimidilalcanol (20 mol\%, 2\% ee) foi usado como autocatalisador assimétrico, o produto foi obtido com $10 \%$ ee e $46 \%$ de rendimento. A mistura formada foi usada em novo ciclo de reação gerando o produto obtido agora com $57 \%$ de ee. A reação foi realizada sucessivamente usando o produto quiral de uma reação como autocatalisador do próximo ciclo, tendo sido observado um aumento do ee até atingir $88 \%$ ee após 4 ciclos. Este processo químico foi o primeiro exemplo de realização de uma autocatálise assimétrica com amplificação da quiralidade. ${ }^{23}$

A relevância deste trabalho reside no fato de que esses iniciadores podem ser resolvidos pela ação de luz polarizada circularmente (CPL - circularly polarized light), estabelecendo uma ligação entre a influência de uma força externa quiral e a autocatálise. Apesar do processo desenvolvido por Soai empregando espécies organozinco em tolueno estar muito distante das condições prebióticas, seria interessante que os mesmos resultados pudessem ser obtidos pela irradiação com CPL na citada reação autocatalítica e na presença de iniciadores racêmicos. Há muito tempo direita- e esquerda-CPL tem sido proposta como uma das origens da quiralidade dos compostos orgânicos. ${ }^{24} \mathrm{~A}$ ocorrência de irradiação forte esquerda ( $l$ )- ou direita ( $r$-CPL na natureza foi observada na formação de estrelas na região da constelação de Orion..$^{25}$ Contudo, devido a muito pequena anisotropia dos compostos orgânicos, apenas enriquecimentos enantioméricos muito pobres foram induzidos por CPL, particularmente nos estágios 


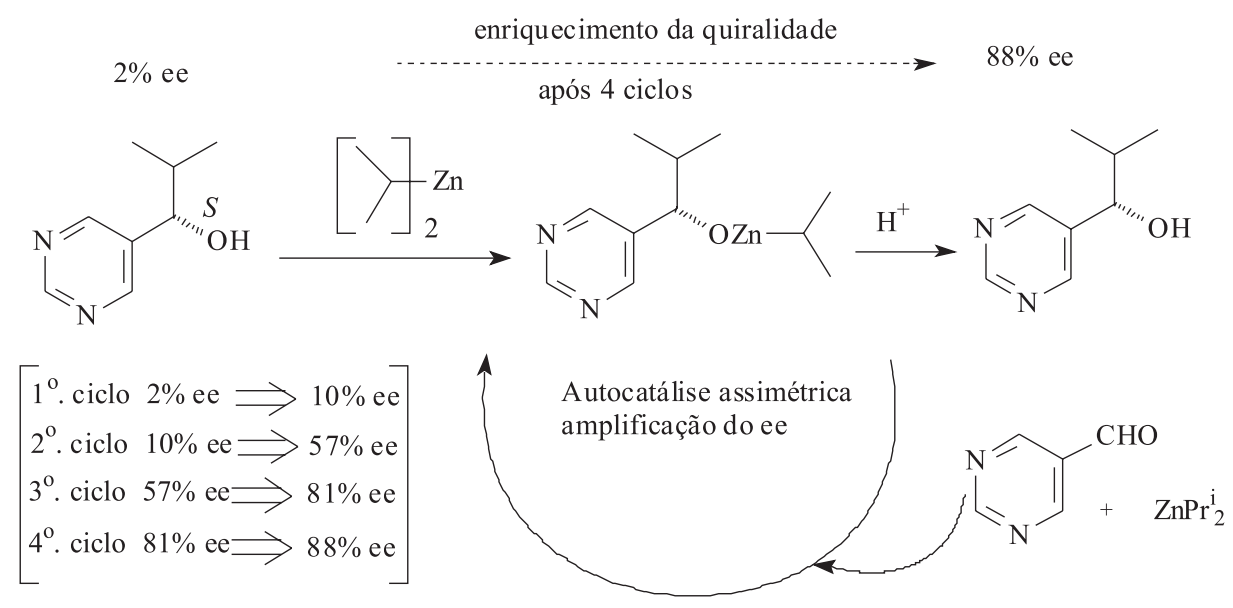

Figura 7. A correlação entre CPL e enriquecimento elevado de composto orgânico em conjunção com autocatálise assimétrica

iniciais de fotoreação assimétrica (Figura 7). Fotodegradação assimétrica da leucina racêmica por $r$-CPL $(213 \mathrm{~nm})$ produziu L-leucina com apenas $2 \%$ ee. Hexa-heliceno também foi formado com baixo ee por fotossíntese assimétrica usando CPL. ${ }^{26}$

Compostos orgânicos quirais com baixo ee induzidos por CPL podem atuar como gatilho na adição enantiosseletiva de $\operatorname{Pr}_{2}^{\mathrm{i}} \mathrm{Zn}$ à pirimidina-5-carbaldeído e, através da subsequente autocatálise do alcanol pirimidílico formado in situ, ampliar seu ee para gerar alcanol pirimidílico enriquecido enantiomericamente, com uma correspondência ao da quiralidade da CPL. Usando L-leucina com $2 \%$ ee como iniciador quiral, o grupo de Soai efetuou a reação com 2-metilpirimidina-5-carbaldeído com $\operatorname{Pr}_{2}^{\mathrm{i}} \mathrm{Zn}$, para produzir o $(R)$-5pirimidinilalcanol com um incremento de $21 \%$ ee (Figura 8 ).

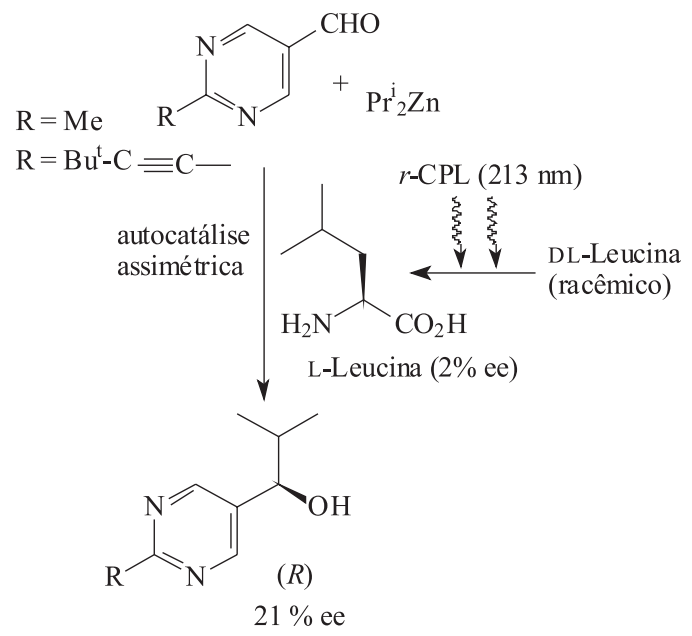

Figura 8. Autocatálise assimétrica com amplificação da quiralidade iniciada por CPL induzida sobre composto orgânico

O grupo japonês encontrou uma "quase perfeita autocatálise assimétrica" usando alcoóis derivados de (S)-2-(terc-butiletinil)-5pirimidila com um ee muito baixo (cerca de $0,00005 \%$ ), para obter um produto enantiomericamente quase puro $(>99,5 \%)$ com rendimento $>99 \% .{ }^{27}$ No decorrer de apenas três ciclos consecutivos de autocatálise assimétrica, o álcool de partida atingiu >99,5\% ee (Figura 9). Os autores constataram que a enantiosseletividade é dependente tanto de fatores estruturais como das condições da reação. Através de uma avaliação tipo screening, encontraram que grupo etinilas com substituintes moderadamente retiradores de elétrons, com volume adequado da parte etinila atuavam mais eficientemente. ${ }^{28}$

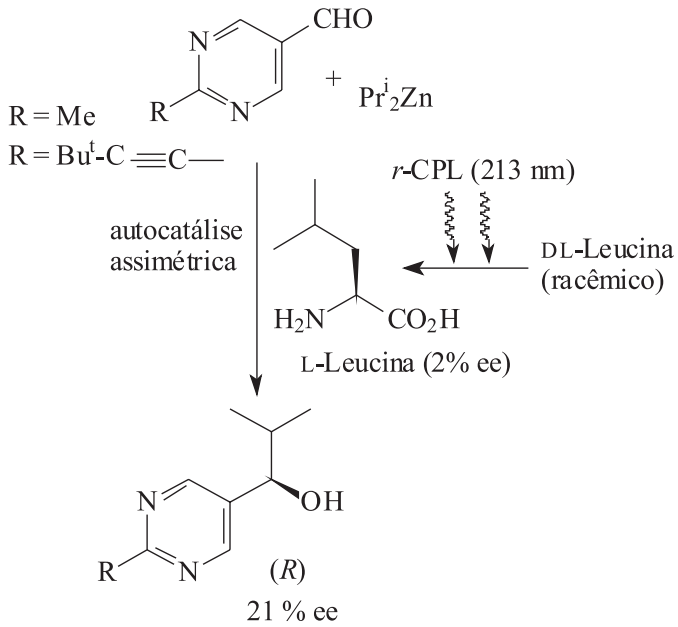

Figura 9. Amplificação da quiralidade de cerca de 0,00005\% ee para um composto quase enantiomericamente puro através da autocatálise assimétrica

Vários compostos orgânicos podem atuar como um iniciador quiral de autocatálise assimétrica. O 2-metilpirimidina-5-carbaldeído foi submetido à adição de $i-\operatorname{Pr}_{2} \mathrm{Zn}$ na presença de $(R)$ - ou $(S)$-mandelato de metila e $(R)$ - ou $(S)$-butan-2-ol, ácido $(R)$ - ou $(S)$-2-fenilpropiônico e óxido de propileno quiral. Em todos esses exemplos os autores observaram através de ciclos sucessivos, significativo enriquecimento enantiosseletivo do alcanol inicial contendo baixo ee $(0,1 \%){ }^{29}$

Um exemplo relevante de autoindução enantiosseletiva foi desenvolvido por Danda e colaboradores na formação de cianoidrinas, pela adição de HCN a aldeídos aromáticos na presença de pequenas quantidades de ciclo- $\left[(R)\right.$-fenilalanil- $(R)$-histidila] (Figura 10).$^{30}$ $\mathrm{O}$ ee do produto $(S)$-2-hidroxi-2-(3-fenoxifenil)acetonitrila subiu, atingindo $92 \%$, com aumento da conversão de 3-fenoxibenzaldeído no transcorrer da reação. Além disso, com uma pequena quantidade do produto $(S)$ - presente na mistura reacional antes da introdução de $\mathrm{HCN}$, a atividade ótica do produto permaneceu em torno de $96 \%$ durante o transcorrer da reação. Os resultados sugerem que a $(S)$-cianoidrina que é produzida, é incorporada no sítio ativo do catalisador. A presença inicial de pequena quantidade da $(S)$-cianoidrina levou à formação da $(S)$-cianidrina com elevada pureza ótica (82-97\% ee), independentemente da pureza ótica do catalisador $(R, R)$-ciclopeptídeo. É relevante o fato de que o emprego do catalisador essencialmente racêmico ( $2 \%$ ee) deu um produto com $43 \%$ de rendimento e $82 \%$ ee, desde que inicialmente estivesse presente pequena quantidade da $(S)$-cianoidrina. Um catalisador preparado a partir do dipeptídeo 


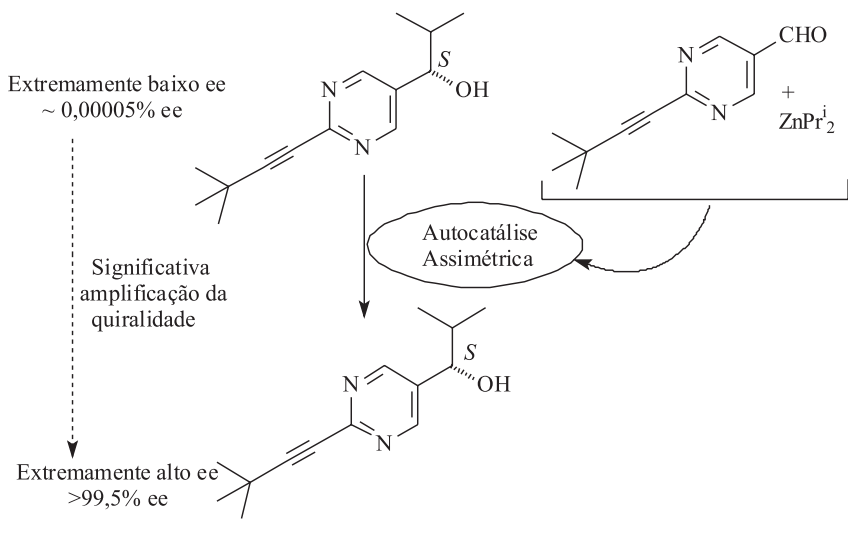

Figura 10. Autoindução enantiosseletiva mediada por ciclo-[(R)-fenilalanil(R)-histidila]

cíclico com $67 \%$ ee e mais (S)-cianoidrina com $92 \%$ ee, deu um produto com $89 \%$ de rendimento e $96 \%$ ee, que é maior do que o ee de ambos os componentes do catalisador. Isto não quer dizer que a pureza enantiomérica da cianoidrina constitui no fator fundamental do ciclo catalítico. Os autores Alberta e Wynberg descreveram também um exemplo de autoindução enantiosseletiva na adição assimétrica de etil-lítio a benzaldeído. ${ }^{31}$

Um exemplo interessante de reação autocatalítica desenvolvida por Asakura e colaboradores envolve a formação de compostos de coordenação em meio aquoso. ${ }^{32} \mathrm{O}$ complexo quiral de cobalto octaédrico cis- $\left[\mathrm{CoBr}\left(\mathrm{NH}_{3}\right)(\mathrm{em})_{2} \mathrm{Br}_{2}\right] \mathrm{Br}_{2}$ pode ser preparado pela reação de um complexo diaquocobalto(II), $\left[\mathrm{Co}\left(\mathrm{H}_{2} \mathrm{O}\right)_{2}\left\{(\mathrm{OH})_{2} \mathrm{Co}(\mathrm{en})_{2}\right\}_{2}\right]\left(\mathrm{SO}_{4}\right)_{2}$, com brometo em água. Apesar de todos os reagentes serem oticamente inativos, quando a reação foi agitada à temperatura ambiente por cerca de 1 min ou a $50{ }^{\circ} \mathrm{C}$ por $5 \mathrm{~min}$, foram obtidos complexos cristalinos oticamente ativos em quase todas as bateladas realizadas. Contudo, o ee variou estocasticamente (Figura 11).

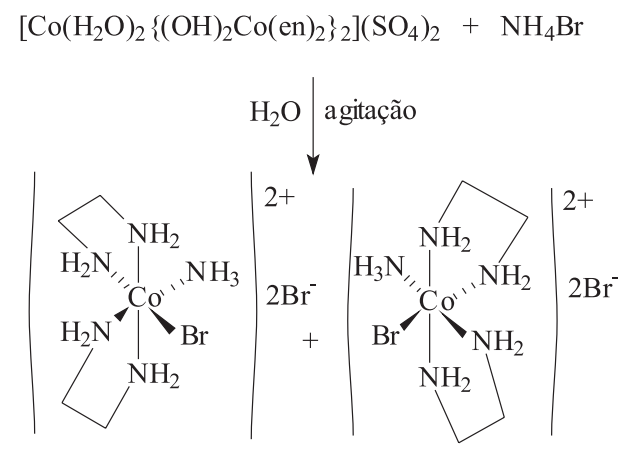

$\Lambda$-enantimômero

$\Delta$-enantimômero

Figura 11. Nucleação autocatalítica de cristais enantioméricos de compostos de coordenação

O complexo quiral cristaliza como um conglomerado no qual cada cristal consiste em $\Lambda$ - ou $\Delta$-enatiômeros. Durante a agitação, um cristal de certo enantiômero pode se automultiplicar por uma nucleação secundária e, deste modo, catalisar sua própria formação. Quando a reação foi agitada na presença de pequena quantidade de cristal de um enantiômero, aquele enantiômero foi produzido preferencialmente. No caso de um enantiômero ser adicionado durante a dissolução, tal preferência não é observada. Isto indica que uma reação autocatalítica que passa por uma nucleação secundária requer a presença de cristais para induzir a quebra da simetria.

Hakansson e colaboradores efetuaram a síntese e a total resolução espontânea de enantiômeros de complexos hepta- e octocoordenaados do tipo $\left[\mathrm{M}(\mathrm{LL})_{3} \mathrm{~L}\right]$ e $\left[\mathrm{M}(\mathrm{LL})_{3} \mathrm{~L} 2\right] \cdot{ }^{33}$ Mais recentemente, estenderam a técnica para enantiômeros os pentacoordenados

$\left[\mathrm{M}(\mathrm{LL})_{2} \mathrm{~L}\right]$, principalmente $\left[\mathrm{Zn}\left(\mathrm{S}_{2} \mathrm{CNEt}_{2}\right)_{2} \mathrm{~L}\right]$, tendo como ligante bidentado o $N, N$-dietilditiocarbamato. Sintetizaram também vários complexos pentacoordenados variando o ligante monodentado, e descobriram que apenas dois deles eram capazes de realizar resolução espontânea: $\left[\mathrm{Zn}\left(\mathrm{S}_{2} \mathrm{CNEt}\right)_{2}(\right.$ vinim $\left.)\right]$ (vinim = 1-vinilimidazol) e $\left[\mathrm{Cd}\left(\mathrm{S}_{2} \mathrm{CNEt}_{2}\right)_{2}\right.$ (lut)] (lut $=2,6$-lutidina). O primeiro cristal que se forma determina a quiralidade dos demais por nucleação secundária. Ambos os cristais $\Lambda$ - ou $\Delta$-enatiômeros podem ser obtidos (Figura 12). ${ }^{34}$

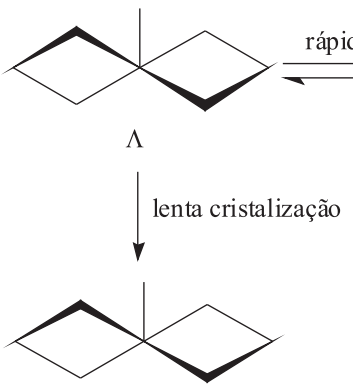

$\Lambda$-cristais

Figura 12. Resolução assimétrica induzida por cristalização

A resolução por cristalização é muito mais atrativa se o processo envolver a racemização simultânea do enantiômero não desejado. Esta combinação de cristalização e racemização em solução é também chamada de resolução espontânea, na qual germens do enantiômero desejado são introduzidos em uma solução supersaturada na qual acontece a racemização. Estes germens crescem resultando em um aumento do material sólido enantiopuro, até o desaparecimento do racemato. Para reduzir a velocidade da nucleação do enantiômero indesejado, a supersaturação pode ser diminuída pela introdução de inúmeros núcleos secundários do enantiômero desejado, pela agitação da solução. O rendimento teórico do enantiômero na fase sólida é quantitativo e na prática é apenas limitado pela solubilidade. Foi demonstrada, recentemente, a completa desracemização usando cristalização com trituração abrasiva próxima das condições de equilíbrio, que é um processo notavelmente simples e uma técnica confiável para atingir estado final enantiomericamente puro destes sistemas. ${ }^{35}$ Um exemplo prático foi obtido com a resolução do éster metílico ou etílico do (S)-Naproxen (os cristais são conglomerados), que é um anti-inflamatório não esteroídeo (Figura 13). ${ }^{36}$

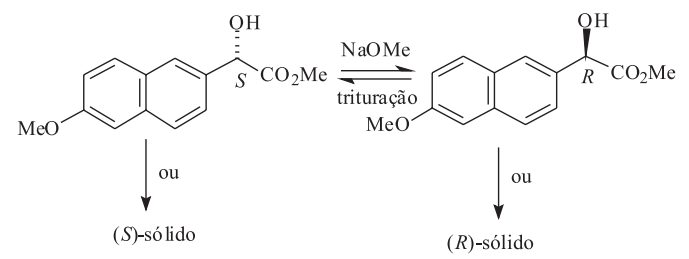

Figura 13. Desracemização in situ por trituração abrasiva

Os efeitos da abrasão durante a trituração (em geral realizada com bolas de vidro) e agitação são tais que os L-cristais e os Dcristais perdem continuamente pequenos fragmentos de L-e Dmicrocristalitos ou de agregados (clusters) quirais. Considerando que a solubilidade de pequenas partículas é maior do que a das maiores (Equação de Gibbs-Thompson), ${ }^{37}$ uma leve concentração de gradientes é criada entre partículas de tamanhos diferentes. Estes microcristais são facilmente dissolvidos e vão alimentando os maiores. Desta maneira, este fenômeno de dissolução e cristalização continuada (conhecido como amadurecimento induzido de 
Ostwald), ${ }^{38}$ é altamente acentuado pela trituração abrasiva. Viedma mostrou recentemente que duas populações de L-cristais e de D-cristais não podem coexistir em solução: uma das populações quirais desaparece através de processo autocatalítico irreversível para gerar a outra. A final e completa pureza quiral parece ser o destino inexorável do curso do processo comum de crescimentodissolução (Figura 14). Viedma investigou misturas de L-cristais e de D-cristais de $\mathrm{NaBrO}_{3}$ contendo no início 5\% L-CEE (cristal ee) (ou D-CEE), que apresentavam após 8 h 100\% L-CEE (ou 100\% D-CEE). Considerando que um racemato naturalmente apresenta um desbalanço dos enantiômeros, Viedma verificou também que misturas simétricas de L-e D-cristais de $\mathrm{NaBrO}_{3}$ mostraram total pureza quiral após $24 \mathrm{~h}$. Ele justificou este resultado como um fenômeno termodinâmico e cinético, realimentado durante o processo de dissolução-crescimento próximo do equilíbrio. A identidade da fase sólida quiral é perdida durante a dissolução do $\mathrm{NaBrO}_{3}$ que é intrinsecamente aquiral (Figura 15). ${ }^{39}$ Viedma generalizou seus resultados aqui resumidos, sugerindo que um processo de dissolução (num caso ideal incrementado pela flutuação de temperatura ou por ciclos secos e úmidos) de aminoácidos (cristalizando como conglomerados) ou ambos os polímeros (proteínas) homoquirais em um sistema fechado, com racemização de moléculas em solução (o tempo geológico é um poderoso agente de racemização), poderia gerar completa pureza quiral na fase sólida. Este processo pode ter desempenhado um papel chave na origem da homoquiralidade biológica na Terra.

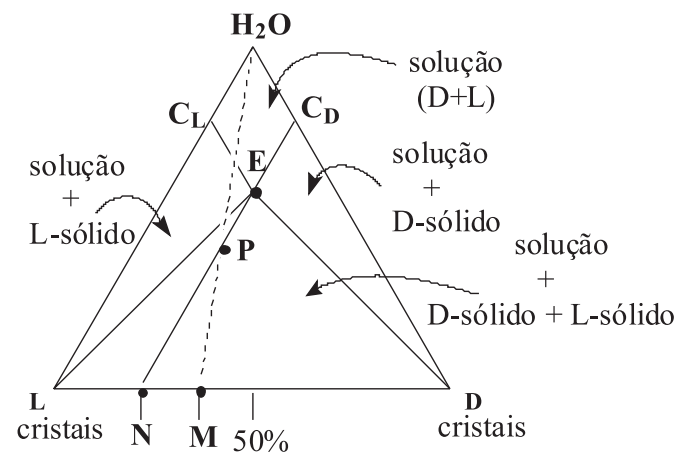

Figura 14. Diagrama ternário de solubilidade $(L+D+$ solvente $)$ para cristalização preferencial. Uma mistura sólida M com uma quantidade limitada de água dá o sistema P. O processo de dissolução dá uma solução de composição E (eutético). A extensão da linha EP leva para a composição $N$, o que indica um aumento no CEE a partir de $M$ para $N$

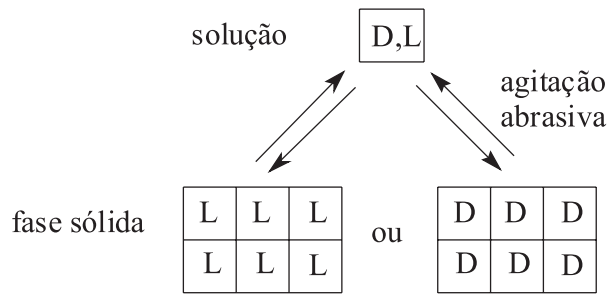

Figura 15. Equilíbrio sólido-solução para uma molécula intrinsecamente aquiral

Uma situação um pouco diferente da representada na Figura 16, foi reportada recentemente por Blackmond e colaboradores ${ }^{40}$ investigando a emergência de uma fase sólida quiral para uma molécula intrinsecamente quiral, iniciando com uma mistura racêmica de cristais enantiomorfos (conglomerados). A imina 1 do 2-metilbenzaldeído com fenilglicinamida $\mathbf{2}$ forma um conglomerado na fase sólida e racemiza rapidamente em solução pela adição de base $\left(t_{1 / 2}\right.$
$<2$ min a $25{ }^{\circ} \mathrm{C}$ com base orgânica DBU em metanol, pKa = 12). O experimento foi realizado com agitação na presença de pérolas de vidro durante 35 dias. Na presença de pérolas de vidro, que proporcionam a energia mecânica para o sistema pela abrasão continuada dos cristais, foi encontrado que o CEE aumenta inexoravelmente para um único estado sólido quiral a partir de um pequeno desbalanço (2$3 \%$ ee) na composição dos cristais iniciais. Os autores observaram também em experimento a parte, que iniciando um processo com a adição de gérmen da fenilglicinamida 2 tendo 0,1 mol \% de pureza enantiomérica, proporciona um viés quiral atingido pela abrasão induzida numa única fase sólida quiral final. A adição da $(S)$-fenilglicina $\mathbf{2}$ ao $(R S)-\mathbf{1}$ provoca a desracemização formando $(S)$-1, enquanto a adição de gérmen da $(R)$-2 leva ao estado quiral $(S)$-1 (Figuras 16 e 17). Os autores argumentam que seus resultados juntamente com o modelo desenvolvido por Viedma, discutido anteriormente, tem profundas implicações para o entendimento da origem de uma única quiralidade nos organismos vivos e, por extensão, para a compreensão da química básica da vida. ${ }^{41}$

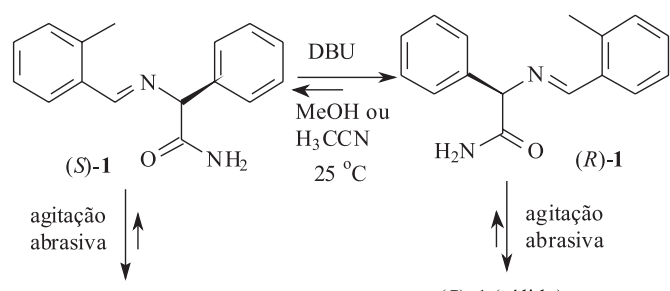

(S)-1 (sólido)

(R)-1 (sólido)

Figura 16. Equilíbrio físico e químico no processo de racemização e cristalização-dissolução

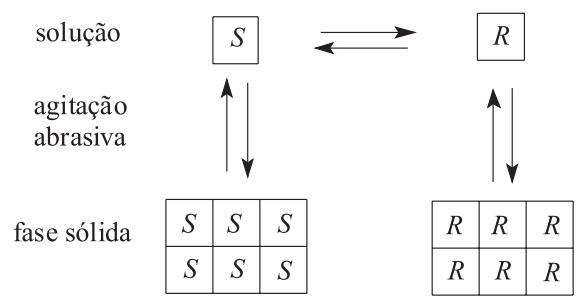

Figura 17. Equilíbrio sólido-solução para uma molécula quiral sofrendo racemização na fase solução

\section{Adsorção quirosseletiva na superfície de cristais}

Considera-se que a adsorção molecular e a auto-organização de biomoléculas na superfície de minerais tenham tido um importante papel na emergência da homoquiralidade no ambiente pré-biótico. ${ }^{42}$ A adsorção preferencial de aminoácidos sobre superfície de minerais quirais, tais como quartzo, ${ }^{43}$ calcita $\left(\mathrm{CaCO}_{3}\right){ }^{44}$ e gipsita $\left(\mathrm{CaSO}_{4}\right),{ }^{45}$ tem sido reportada. Estes minerais devem ter sido dos mais abundantes no éon arqueano (3800 a 2500 milhões de anos passados), na metade do período pré-cambriano. O quartzo, o clorato de sódio e o cinábrio possuem faces hemiédricas que não são idênticas com suas imagens especulares. Já a calcita tem faces escalenoédricas enantioméricas que adsorvem ácido D-aspártico, enquanto as faces de sua imagem especular adsorvem seletivamente o ácido L-aspártico. ${ }^{41}$ Aminoácidos diferentes apresentaram seletividade diferentes: a alanina tem comportamento similar ao do ácido aspártico, enquanto a lisina não é adsorvida seletivamente pela calcita. Esta seletividade de adsorção do ácido aspártico foi recentemente comprovada por outros autores. ${ }^{46}$ Bonner e Kavasmaneck encontraram que o $l$-quartzo adsorve preferencialmente cloridrato de L-alanina a partir de uma mistura racêmica, enquanto que $d$-quartzo favorece a adsorção de D-alanina. ${ }^{47}$ 


\section{FORMAÇÃO E AMPLIFICAÇÃO DE OLIGOPEPTÍDEOS HOMOQUIRAIS}

Uma pergunta fundamental relacionada com a origem da homoquiralidade na Terra, é como aminoácidos com muito baixo ee foram convertidos em oligopetídeos homoquirais. Recentemente, Ghadari e colaboradores sugeriram que peptídeos formados exclusivamente por D- ou L-aminoácidos se replicaram apenas sobre moldes de mesma quiralidade. ${ }^{48} \mathrm{~A}$ cópia resultante pode atuar como um molde para uma subsequente síntese estereosseletiva. Os autores ilustraram esta replicação através de condensações dirigidas por moldes entre um par de peptídeos eletrofilicos (E) e nucleofílicos $(\mathrm{Nu})$. Cada par seria constituído inteiramente por aminoácidos de mesma quiralidade, tanto $\mathrm{L}\left(\mathrm{E}^{\mathrm{L}}\right.$ e $\left.\mathrm{N}^{\mathrm{L}}\right)$ ou seu antípoda $\mathrm{D}\left(\mathrm{E}^{\mathrm{D}}\right.$ e Nu $\left.\mathrm{Nu}^{\mathrm{D}}\right)$. Por conseguinte, as condensações destes substratos poderiam gerar até quatro moldes $(\mathrm{M})$, tanto homoquiral ( $\mathrm{M}^{\mathrm{LL}}$ e $\left.\mathrm{M}^{\mathrm{DD}}\right)$ como heteroquiral $\left(\mathrm{M}^{\mathrm{LD}}\right.$ e $\left.\mathrm{M}^{\mathrm{DL}}\right)$. A partir de uma mistura racêmica de peptídeos eletrofílicos e nucleofílicos, eram formadas sequências preferencialmente homoquirais. Contudo, o molde $\mathrm{M}^{\mathrm{LL}}$ acelerava autocatalicamente sua produção própria em misturas contendo fragmentos $\mathrm{N}^{\mathrm{L}} \mathrm{e} \mathrm{E}^{\mathrm{L}}$, enquanto que a adição de $\mathrm{M}^{\mathrm{DD}}$, $\mathrm{M}^{\mathrm{DL}}$, ou $\mathrm{M}^{\mathrm{LD}}$ a esta reação não apresentava influência significante na velocidade da reação. A reação entre $\mathrm{E}^{\mathrm{L}}$ e $\mathrm{N}^{\mathrm{L}}$ na presença de quantidades equimolares dos quatro moldes homo- e heteroquiral exibia uma velocidade similar daquela do processo contendo apenas $\mathrm{M}^{\mathrm{LL}}$. Em experimentos independentes, foi demonstrado que a formação do molde heteroquiral $\mathrm{M}^{\mathrm{LD}}$ não era afetada pela presença ou ausência de todos os outros moldes (Figura 18).

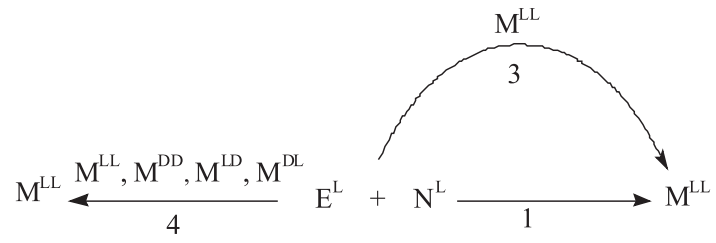

$$
\begin{aligned}
& \mathrm{E}^{\mathrm{D}}+\mathrm{N}^{\mathrm{D}} \longrightarrow \mathrm{M}^{\mathrm{DD}}
\end{aligned}
$$

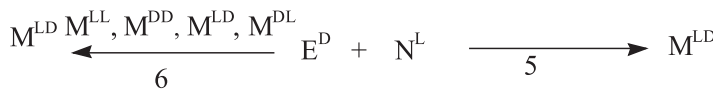

Figura 18. Formação quirossseletiva de moldes homoquirais. As rotas (3) $e$ (4), (5) e (6) possuem velocidades similares para a formação dos produtos

Apenas os moldes homoquirais atuavam como autocatalisadores quirosseletivos, enquanto que os competitivos fragmentos heteroquirais eram formados através de reações não catalisadas. Até mesmo uma mutação heteroquiral pode interromper a autorreplicação de sequências homoquirais. É possível prever qual homoquiralidade pode emergir de uma mistura randômica de substratos homo- e heteroquirais e seria até possível sugerir qual homoquiralidade vai acontecer antes do aparecimento do código genético. Apenas oligopeptídeos homoquirais parecem formar verdadeiras estruturas helicoidais. ${ }^{49}$ Evidências recentes reforçam estes estudos, uma vez que a inclusão de D-aminoácidos em um oligopeptídeo constituído de L-aminoácidos destrói o seu perfeito arranjo helicoidal, talvez devido aos efeitos estéricos das cadeias laterais. ${ }^{50}$

A amplificação da quiralidade durante a polimerização é um fator relevante, que pode estar envolvida nos estágios evolucionários antes do aparecimento de estruturas biológicas totalmente homoquirais. $\mathrm{O}$ caso de aminoácidos ativados como $\mathrm{N}$-carboxianidridos de aminoácidos (NCA-aminoácidos) foi reconhecido há muito tempo. ${ }^{51}$ A polimerização de NCA-aminoácido é disparada por um iniciador nucleofílico, produzindo cadeias peptídicas e liberando $\mathrm{CO}_{2}$. A po- limerização de racematos NCA-aminoácidos tendo cadeias hidrofóbicas (triptofano, leucina e isoleucina) em soluções aquosas origina oligopetídeos caracterizados pelo alto grau de homoquiralidade em sua sequência. ${ }^{52}$ Quando a polimerização foi realizada em água usando uma mistura enantiomericamente enriquecida de monômeros (20\% ee de NCA-leucina, ou 20\% ee NCA-L-glutmato), foi detectada amplificação quiral de frações homoquirais de oligopepítdeo de até $73 \%$ para $(\mathrm{Leu})_{3}$ e $71 \%$ para $(\mathrm{Glu})_{7}$ homoquirais. ${ }^{53}$ Estudos de cooperatividade de polimerização mostraram que a probabilidade da adição de monômero, tanto L- como D-aminoácido, para o crescimento final dependia da configuração das duas últimas unidades de crescimento do oligômero final, assim como pela amplificação cooperativa resultante da formação de uma $\alpha$-hélice. ${ }^{49}$

Em muitas polimerizações, não há duvida de que a estrutura secundária de polímeros esteja envolvida na amplificação da quiralidade. Um caso notável é a polimerização de isocianatos $(\mathrm{R}-\mathrm{N}=\mathrm{C}=\mathrm{O})$ para produzir poli(isociantos), um polímero conhecido como Nylon-1. ${ }^{54}$ Este Nylon-1 mostrou uma não usual forte preferência por conformações helicoidais em sua cadeia. Embora sendo helicoidal, este polímero pode ser sintetizado a partir de monômeros aquirais (por exemplo, $\mathrm{R}=n$-hexila), gerando igual número de cadeias direita- e esquerda-helicoidais. Contudo, o polímero não é usualmente sensível a influências quirais. A introdução de uma pequena quantidade de um isocianato quiral $(\mathrm{R}=(R)$-2,6-dimetileptila) pode induzir um elevado ee de uma hélice. Assim, uma cadeia polimérica com apenas $15 \%$ de unidades monoméricas quirais e $85 \%$ de $n$-hexilisocianato gera o mesmo grau de atividade ótica que uma cadeia consistindo inteiramente de unidades quirais. ${ }^{55}$ Este tipo de amplificação quiral, consistindo em gerar um excesso de preferência helicoidal, pela influência de um pequeno número de unidades quirais (os "sargentos") sobre um grande número de unidades aquirais (os "soldados") é conhecida como um efeito sargento e soldado.

Outro exemplo é um poli-isocianato sintetizado pela copolimerização randômica de uma mistura racêmica de monômeros (contendo apenas um leve excesso de um enantiômero), que provocou um grande excesso da forma helicoidal gerada a partir da homopolimerização do correspondente monômero enantiomericamente puro. Por exemplo, uma cadeia polimérica construída a partir de um monômero com apenas $12 \%$ de ee do $(R)$-2,6-dimetileptilisocianato apresentou um espectro DC (dicroísmo circular) idêntico ao de um polímero sintetizado de um monômero quase enantiomericamente puro. Esta geração de um excesso da forma helicoidal, preferida pelo enantiômero em excesso, é chamada de "regra da maioria", a partir de um componente minoritário tomando parte da forma helicoidal imposta pelas unidades majoritárias. ${ }^{56}$

Outro experimento mostrando uma forte resposta cooperativa para a informação quiral do polímero helicoidal é a polimerização do $(R)$-1-deutério- $n$-hexilisocianato, $[\alpha]_{\mathrm{D}}=+0,65$ (puro), para dar o correspondente poli(isocianato) com atividade ótica $[\alpha]_{D}=-444$ (hexano). A substituição isotópica de um único átomo de hidrogênio por deutério no monômero $n$-hexilisocianato por um modo enantiosseletivo dispara um quase completo domínio de um senso helicoidal no polímero. ${ }^{57} \mathrm{O}$ mecanismo de amplificação dando origem a excesso helicoidal tem sido interpretado como um equilíbrio conformacional do efeito isotópico, indicando um mecanismo aditivo eficiente e cooperativo atuando na cadeia polimérica. Sendo preciso ou não, este é um exemplo da extrema sensibilidade deste sistema para um viés quiral. A amplificação da quiralidade em outros polímeros helicoidais, tais como polifenilacetilenos, polisocianetos e polissilanos, tem sido estudada tanto experimental quanto teoricamente. ${ }^{58}$

Recentemente, Lahav e colaboradores vêm apresentando uma nova proposta para a origem da homoquiralidade de peptídeos, baseados na formação e atuação de folhas- $\beta$ que agiriam como moldes num processo que se desenvolveria numa sequência sucessiva de 
ações em cascata. ${ }^{59} \mathrm{~A}$ proposta mais comumente aceita é a formação primitiva de sequência longa de peptídeos homoquirais, a partir de precursores racêmicos através do envolvimento de moldes hélices- $\alpha$ como sugerido por Wald, ${ }^{60}$ ou de folhas- $\beta$ pregueadas enantiomorfas segundo Brack e Spach, ${ }^{61}$ conforme discutimos anteriormente. Lahav e colaboradores propuseram a possibilidade de gerar petídeos isotáticos e copeptídeos contendo até 25 resíduos de mesma quiralidade, a partir de $\alpha$-aminoácidos ativados ou não racêmicos em diversos ambientes reacionais. ${ }^{62}$ Em algumas reações, folhas- $\beta$ racêmicas semelhantes a partículas coloidais emergem e operam como moldes estereosseletivos na formação de peptídeos homoquirais. Tais moldes deveriam apreciar uma considerável vantagem enantiosseletiva em um ambiente pré-biótico. A dessimetrização de peptídos isotáticos para formar bibliotecas de misturas diastereosseletivas foi demonstrada usando-se ésteres enantiopuros de $\alpha$-amionoácidos como iniciadores (Figura 19). A distribuição dos oligopeptídeos diastereoisoméricos foi analisada por MALDI-TOF-MS e MS/MS, a partir de monômeros enantiosseletivos marcados com deutério. No mundo primitivo, tais $\alpha$-amionoácidos não racêmicos poderiam ter sido formados tanto por cristalização autocatalítica de racematos, ou a partir de fontes extraterrestres. Finalmente, aplicando estes métodos sintéticos seria possível criar peptídeos homoquirais, que poderiam operar como catalisadores primitivos assimétricos que deveriam preceder as primeiras enzimas.

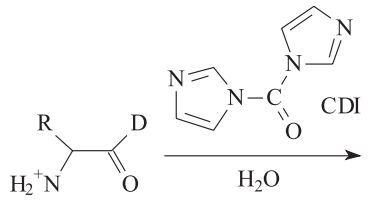

$D L$ - $\alpha$-aminoácidos Leu: $\mathrm{R}=-\mathrm{CH}_{2} \mathrm{CH}\left(\mathrm{CH}_{3}\right)_{2}$ Phe: $-\mathrm{CH}_{2} \mathrm{Ph}$ Val: $-\mathrm{CH}\left(\mathrm{CH}_{3}\right)_{2}$

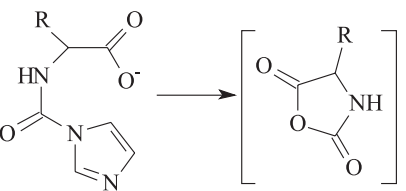

Imidazolilcarbonilaminoácido $\quad D L$-NCA

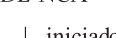

$$
\begin{aligned}
& \text { Patículas coloidais compostas a } \\
& \text { partir de misturas isotáticas e } \\
& \text { racêmicas de oligopetídeos montados } \\
& \text { tanto como folhas- } \beta \text { ou onduladas } \\
& \text { folhas- } \beta \\
& \text { Elongação regiosseletiva } \\
& \text { Forção de oligopeptídeos } \\
& \text { racêmicos homoquirais (isotáticos) } \\
& \text { maiores e co-peptídeos }
\end{aligned}
$$

Figura 19. Proposta para o processo de elongação em cascata levando à formação de oligopeptídeos racêmicos homoquirais maiores a partir de monômeros dissolvidos em água

\section{EMERGÊNCIA DA HOMOQUIRALIDADE NA FASE SOLUÇÃO VIA ENGENHARIA DE CRISTAL DE AMINOÁCIDOS}

Foi divulgado recentemente que soluções de aminoácidos altamente enriquecidas em um enantiômero podem ser preparadas a partir de misturas sólidas quase racêmicas, através da manipulação do comportamento de fase do aminoácido. Sob condições de isotermas de equilíbrio líquido-sólido, um composto quiral não racêmico e não enantiopuro em água ou outro solvente, geralmente, exibe característica composição em solução conhecida como seu eutético (ponto eutético em sistemas ternários de enantiômeros e solvente), independentemente do ee do composto quiral empregado. ${ }^{63} \mathrm{O}$ grupo de Blackmond mostrou que forte amplificação assimétrica da solução é obtida para alguns amionoácidos em seus pontos eutéticos. Por exemplo, a serina com $1 \%$ ee exibe virtualmente uma solução enantiopura de $99 \%$ ee, sob as condições de equilíbrio sólido-líquido em água a $25{ }^{\circ} \mathrm{C} .{ }^{64} \mathrm{Os}$ autores acreditam que seus resultados sugerem que aminoácidos podem ter tido um papel importante na evolução biomolecular homoquiral. Pode-se imaginar a coexistência de aminoácidos sólidos e dissolvidos sob as condições ambientais de uma paisagem pré-biótica, e um elevado ee pode surgir a partir de um pequeno ee inicial, se: (1) o aminoácido forma um composto racêmico (cocristal) em lugar de um conglomerado; (2) o aminoácido mostra elevada pureza enantiomérica em seu eutético; (3) o aminoácido atua com alta seletividade como um catalisador assimétrico na transformação de fase em solução. Os estudos de Blackmond mostram que a serina tem comportamento que atende aos dois primeiros critérios. ${ }^{65}$

Hayashi e colaboradores mostraram que uma solução de prolina em clorofórmio apresenta elevado ee quando comparada com outros solventes como etanol ${ }^{66}$ Posteriormente, foi demonstrado que uma molécula de $\mathrm{CHCl}_{3}$ é incorporada na estrutura dos cocristais da D,Lprolina racêmica. ${ }^{67}$ Este resultado está de acordo como o modelo desenvolvido por Blackmond para predição de ee de eutético, ee eut, baseado na relação de solubilidade $(\alpha)$ para aminoácido racêmico (rac) comparado com o enantiopuro (ep) (Figura 20). ${ }^{68}$ Quanto menor $\alpha(\alpha<<1)$ maior será o ee da solução.

$$
\mathrm{ee}^{\mathrm{eut}}=\frac{1-\left[\frac{\alpha^{2}}{4}\right]}{1+\left[\frac{\alpha^{2}}{4}\right]} \quad \alpha=\frac{[\mathrm{rac}]}{[\mathrm{ep}]}
$$

Figura 20. Cálculo do ee eut segundo Blackmond

A incorporação de moléculas de solventes para formar estruturas sólidas conhecidas como solvatos é bem conhecida e o conceito que isto afeta a composição de eutéticos não tem sido muito enfatizado. As interações de ligação hidrogênio que levam para a formação do solvato devem alterar a razão de solubilidade $\alpha$, com a concomitante alteração do ee da fase solução. O potencial deste conceito resulta em ampliar o enriquecimento ee na fase solução em decorrência da ligação hidrogênio de aditivos nas estruturas da fase sólida de cocristais de aminoácidos. Blackmond e seus colaboradores encontraram que a valina e fenilalanina, principalmente, formam interações fortes de seus racematos no estado cristalino (cocristais) com alguns ácidos carboxílicos, principalmente com ácido fumárico. A valina cocristaliza com ácido fumárico numa relação $2: 1$, tanto na forma racêmica quanto com o enantiômero puro. Por sua vez, a fenilalanina cocristaliza com o ácido fumárico numa relação $1: 1$. Assim a dissolução cinética preferencial de racematos de valina e fenilalanina em água forneceu soluções com cerca de $99 \%$ ee. ${ }^{69}$

Os resultados acima discutidos mostram que o excesso enantiomérico de uma solução de aminoácido, pode ser significativamente aumentado pela incorporação de uma pequena molécula aquiral em seu racemato sólido, pela formação de cocristais. Eles demonstram também não apenas que a evolução de uma única quiralidade em solução, a partir de compostos formados com baixo ee, não é apenas limitada a alguns poucos aminoácidos, como a serina que exibe eutético com elevado ee na ausência de aditivos, mas que várias combinações de aditivos com aminoácidos, podem fornecer soluções altamente enriquecidas em um enantiômero a partir de amostras aproximadamente racêmicas. Isto sugere uma rota geral e fácil para a homoquiralidade molecular, que pode ter relevância em ambiente pré-biótico. Os ciclos de chuvas e evaporação naquele período poderiam estabelecer equilíbrio sólido-solução em poços (ou lagos) 
contendo aminoácidos e moléculas parceiras com adequadas ligações hidrogênio poderiam resultar em soluções enantiopuras a partir de um pequeno desbalanço inicial de enantiômeros de aminoácidos.

\section{Uma perspectiva oriunda de meteoritos carbonáceos}

Os meteoritos carbonáceos condrictos são fragmentos de asteroides primitivos que contêm carbono orgânico e oferecem uma visão dos processos químicos abióticos que precederam o surgimento da vida. Seus conteúdos orgânicos mostram diversas estruturas como macromoléculas semelhantes ao querosene, e simples compostos solúveis que vão de aminoácidos polares, polióis e até hidrocarbonetos não polares. ${ }^{70}$ Alguns destes compostos têm correspondência nas biomoléculas terrestres, e alguns dos aminoácidos mostram característica L-assimetria, sugerindo sua possível contribuição para a evolução molecular terrestre e a origem da homoquiralidade biológica. A composição elementar destes fragmentos de asteroides é considerada muito semelhante à do Sol e são reconhecidos como parecidos aos primitivos agregados nebulares solares. Esses meteoritos representam a única amostra da evolução química disponível para análise,,$^{71} \mathrm{e}$ os $\alpha$-metilaminoácidos (Figura 21) que eles trouxeram para a terra têm sido investigados como uma fonte em potencial para a homoquiralidade. A distribuição isotópica confirma que eles têm origem extraterrestre. ${ }^{72}$

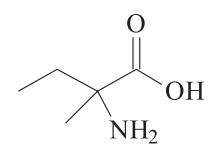

isovalina $15,2 \%$ ee<smiles>CC(C)C(C)(N)C(=O)O</smiles>

$\alpha-$ Me-valina

$2,8 \%$ ee

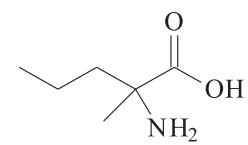

$\alpha$-Me-norvalina $2,8 \%$ ee

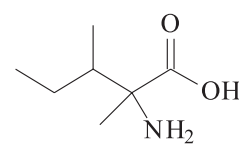

$\alpha-$ Me-isoleucina $7,0 \%$ ee
Figura 21. $\alpha$-Metilaminoácidos encontrados em meteoritos e seus correspondentes ee para os L-enantiômeros

Os $\alpha$-metilaminoácidos (não podem racemizar) podem servir como germens para homoquiralidade terrestre, desde que atendam a duas condições: i) devem ser capazes de transferir sua quiralidade para biomoléculas tais como aminoácidos e açúcares, e ii) deve existir um mecanismo para a amplificação quiral dos aminoácidos dos meteoritos ou dos aminoácidos proteinogênicos até a quase homoquiralidade. Recentemente, o grupo de R. Breslow demonstrou que L- $\alpha$-metilvalina $96 \%$ enantiopura pode transaminar fenilpiruvato para L-fenilalanina com até $37 \%$ ee, e piruvato para L-alanina com até $20 \%$ ee através de catálise com sais de cobre. ${ }^{73}$ Neste estudo, ficou demonstrado também que esse modesto ee encontrado nos meteoritos pode ser amplificado através da dissolução cinética preferencial de cristais da L-alanina mais rapidamente do que os cristais racêmicos. Iniciando com 5\% ee da L-alanina obtiveram até $53 \%$ ee. Os autores reivindicam que seus resultados demonstram que ambas as condições acima são necessárias para os $\alpha$-metilaminoácidos dos meteoritos serem uma fonte plausível da homoquiralidade biomolecular neste planeta, e em qualquer lugar do universo. As condições empregadas para a amplificação homoquiral podem reproduzir o ambiente pré-biótico. A amplificação via evaporação da água pode ter ocorrido na Terra pré-biótica em um lago secando próximo a um meteorito. A disso- lução preferencial pode ter ocorrido quando rio e água de chuva passaram sobre uma mistura de aminoácido, dissolvendo o único aminoácido com enantiopureza enriquecida e carregando-o rio abaixo. Após tal enriquecimento, a biologia pôde iniciar e produzir organismos dominantes e fazer uso dos enantiômeros dominantes, neste planeta e em qualquer outro do universo.

\section{CONCLUSÃO}

A lei da evolução biológica foi formulada por C. Darwin como uma seleção pela "sobrevivência dos mais bem adaptados". O sucesso de uma mutação e uma nova espécie depende, de acordo com Darwin, da sua habilidade de se adaptar ao meio ambiente; mas esta lei evidentemente não funciona para um fluido pré-biótico, e a lei não pode explicar porque um dos enantiômeros domina a evolução na sua origem a partir de racematos. Pressupõe-se que a justificativa para a origem da vida implica que a homoquiralidade veio primeiro e a autorreunião das moléculas da vida aconteceu em um fluido quiral ordenado.

A origem definitiva da assimetria no universo é uma questão em aberto. Contudo, durante a última década, uma série de experimentos relativamente simples tem demonstrado a possibilidade de se produzir produtos oticamente ativos a partir de materiais aquirais. O químico orgânico sintético faz uso de um indutor quiral ou de um catalisador quiral para introduzir num reagente uma assimetria e, deste modo, gerar produtos com elevada homoquiralidade. Num ambiente pré-biótico, este indutor quiral pode ter vindo de outro planeta através de asteroides que atingiram intensamente a Terra em seus primórdios, ou mesmo de choques com cometas que nos visitaram. Outra possibilidade pode ter ocorrido através da incidência de raios de luz circularmente polarizada quiral (CPL) oriunda de outras galáxias, ou mesmo da nossa, que realizaram decomposições fotoquímicas, criando um desbalanceamento quiral em moléculas originalmente racêmicas.

Entretanto, este indutor quiral primordial não necessariamente precisa ter origem extraterrestre. Moléculas aquirais podem se cristalizar em sistemas que possuem faces quirais como o quartzo, a calcita e outros minerais abundantes na crosta terrestre. A adsorção preferencial de enantiômeros na superfície quiral daqueles minerais pode resultar na resolução de racematos, e a polimerização destes enantiômeros poderia dar origem às moléculas responsáveis pela vida, as proteínas e os carboidratos. Reações autocatalíticas tipo Soai demonstram que a partir de um leve desbalanceamento em racematos, pode resultar numa amplificação quiral quase perfeita de um único enantiômero.

Na década atual vêm se desenvolvendo outras possibilidades relevantes para a amplificação quiral oriunda de muito pequeno excesso enantiomérico. Moléculas racêmicas que formam conglomerados cristalinos agora são facilmente transformadas em uma única forma quiral a partir da dissolução abrasiva preferencial. Foi demonstrado que enantiômeros que se racemizam em solução são facilmente cristalizados em uma única forma quiral, e que este fenômeno ocorre com derivados de aminoácidos. O conhecimento do comportamento do estado cristalino vem demonstrando, desde os tempos de Pasteur, a sua relevância para o entendimento de importantes propriedades relacionadas com a discriminação da quiralidade, e que tem fundamental importância para o entendimento da origem e a amplificação da quiralidade nas biomoléculas.

A resenha aqui apresentada procurou se deter principalmente nos aspectos químicos discutidos na literatura recente. Entretanto, trata-se de tema interdisciplinar e uma discussão envolvendo fenômenos físicos poderá ser encontrada em alguns excelentes livros recentemente editados. ${ }^{74}$ 


\section{AGRADECIMENTOS}

Ao apoio financeiro das entidades de fomento FAPESP e CNPq.

\section{REFERÊNCIAS E NOTAS}

1. Pasteur, L.; Leçons de chimie professées em 1860 par MM. Pasteur, Cahours, Wurtz, Berthelot, Sainte-Claire Devile, Barral et Dumas, Hachette: Paris, 1861

2. Lee, T. D.; Yang, C. N.; Phys. Rev. 1956, 104, 254.

3. Quack, M.; Stohner, J.; Wilike, M.; Annu. Rev. Phys. Chem. 2008, 59, 741.

4. Mason, S.; Chem. Soc. Rev. 1988, 17, 347.

5. Pasteur, L.; C. R. Acad. Sci. Paris 1848, 26, 535.

6. Eliel, E. L.; Wilen, S. H.; Mander, L. N.; Stereochemistry of Organic Compounds, Wiley-Insterscience: New York, 1994.

7. Siegel, J. S.; Chirality 1998, 10, 24.

8. Guijarro, A.; Yus, M.; The Origin of Chirality in the Molecules of Life, Royal Society of Chemistry: Cambridge, 2008; Viedma, C.; Astrobiology 2007, 7, 312; Nielsen, P. E.; Orig. Life Evol. Biosph. 2007, 37, 323.

9. Tamura, R.; Takahashi, H.; Hirotsu, K.; Nakajima, Y.; Ushio, T.; Toda, F.; Angew. Chem., Int. Ed. 1988, 37, 2876; Takahashi, H.; Tamura, R.; Ushio, T.; Nakajima, Y.; Hirotsu, K.; Chirality 1988, 10, 705.

10. Kipping, W. S.; Pope, W. J.; J. Chem. Soc. Trans. 1898, 73, 60.

11. Kondepudi, D. R.; Kaufman, R. J.; Singh, N.; Science 1990, 250, 975.

12. McBride, J. M.; Carter, R. L.; Angew. Chem., Int. Ed. 1991, $30,293$.

13. Kondepudi, D. K.; Bullock, K. L.; Digitis, J. A.; Yarborough, P. D.; J. Am. Chem. Soc. 1995, 117, 401.

14. Pincock, R. E.; Perkins, R. R.; Wilson, K. R.; Science 1971, 174, 1081.

15. Kondepudi, D. K.; Laudadio, J.; Asakura, K.; J. Am. Chem. Soc. 1999, 121, 1448.

16. Soloshonok, V. A.; Ueki, H.; Yasumoto, M.; Mekala, S.; Hirschi, J. S.; Singleton, D. A.; J. Am. Chem. Soc. 2007, 129, 12112.

17. Cintas, P.; Angew. Chem., Int. Ed. 2008, 47, 2918.

18. Chickos, J. S.; Garin, D. L.; Hitt, M,; Schilling, G.; Tetrahedron 1981, 37, 2255.

19. Pracejus, G.; Justus Liebigs Ann. Chem. 1959, 622, 10; Kwart, H.; Hoster, D. P.; J. Org. Chem. 1967, 32, 1867; Garin, D. L.; Greco, D. J. C.; Kelley, L.; J. Org. Chem. 1977, 42, 1249.

20. Jacques, J.; Collet, A.; Wilen, S. H.; Enantiomers, Racemates, and Resolutions, Krieger: Malabar, 1988, p. 159-165.

21. Franck, F. C.; Biochim. Biophys. Acta 1953, 11, 459.

22. Para uma revisão geral da reação Soai ver Soai, K.; Kawasaki, T.; Top. Curr. Chem. 2007, 128, 138.

23. Soai, K.; Shibata, T.; Morioka, H.; Choji, K.; Nature 1995, 378, 767.

24. Kuhn, W.; Knopf, E. Z.; Phys. Chem. B 1930, 7, 292; Bernstein, W. J.; Calvin, M.; Buchardt, O.; J. Am. Chem. Soc. 1972, 94, 494; Inoue, Y.; Chem. Rev. 1992, 92, 741; Feringa, B. L.; van Delden, R. A.; Angew. Chem., Int. Ed. 1999, 38, 4128.

25. Bailey, J.; Chrysostomou, A.; Hough, J. H.; Gledihil, T. M.; McCall, A.; Clarck, S.; Menard, F.; Tamura, M.; Science 1988, 281, 672.

26. Suarez, M.; Schuster, G. B.; J. Am. Chem. Soc. 1995, 117, 6732.

27. Sato, I.; Yanagi, T.; Soai, K.; Chirality 2002, 14, 166; Lutz, F.; Kawasaki, T.; Soai, K.; Tetrahedron: Asymmetry 2006, 17, 486; Lutz, F.; Igarashi, T.; Asahina, M.; Tsukiyama, K.; Kawasaki, T.; Soai, K.; J. Am. Chem. Soc. 2008, 130, 2956.

28. Sato, I.; Urabe, H.; Ishiguro, S.; Shibata, T.; Soai, K.; Angew. Chem., Int. Ed. 2003, 42, 315.

29. Micskei, K.; Pota, G.; Caglioti, L.; Palyi, G.; J. Phys. Chem. A 2006, 110, 5982; Shibata, T.; Yamamoto, J.; Matsumoto, N.; Yonekubo, S.; Osanai, S.; Soai, K.; J. Am. Chem. Soc. 2006, 120, 12157; Kawasaki, T.; Shimizu, M.; Suzuki, K.; Sato, I.; Soai, K.; Tetrahedron: Asymmetry 2004, 15, 3699.

30. Danda, H.; Nishikawa, H.; Otaka, K.; J. Org. Chem. 1991, 56, 6740.
31. Alberta, A. H.; Wynberg, H.; J. Am. Chem. Soc. 1989, 111, 7265.

32. Asakura, K.; Kobayashi, T.; Mizusawa, Y.; Ozawa, T.; Osanai, S.; Yoshikawa, S.; Physica D 1995, 84, 72; Asakura, K.; Kondepudi, D. K.; Martin, R.; Chirality 1998, 10, 343.

33. Lennartson, A.; Vestergree, M.; Hakansson, M.; Chem. Eur. J. 2005, 11, 1757.

34. Lennartson, A.; Hakansson, M.; Angew. Chem., Int. Ed. 2009, 48, 5869.

35. Noorduin, W. L.; van der Asdonk, P.; Meeks, H.; van Enckvort, J. P.; Kaptein, B.; Leeman, M.; Kellogg, R. M.; Vlieg, E.; Angew. Chem., Int. Ed. 2009, 48, 3278.

36. Noorduin, W. L.; Kaptein, B.; Meekes, H.; van Enckevort, J. P.; Kellogg, R. M.; Vlieg, E.; Angew. Chem., Int. Ed. 2009, 48, 4581.

37. Joesten, R. L.; Mineralogical Society of America Short Course Notes 26, Mineralogical Society of America: Chantilly, 1991, p. 507.

38. Para uma revisão recente ver Noorduin, W. L.; Vlieg, E.; Kellogg, R. M.; Kaptein, B.; Angew. Chem., Int. Ed. 2009, 48, 9600.

39. Viedma, C.; Astrobiology 2007, 7, 312

40. Noorduin, W. L.; Izumi, T.; Millemaggi, A.; Leeman, M.; Meeckes, H.; van Enckevort, W. J. P.; Kellogg, R. M.; Kaptein, B.; Vlieg, E.; Blackmond, D. C.; J. Am. Chem. Soc. 2008, 130, 1158.

41. Izumi, T.; Blackmond, D. G.; Chem. Eur. J. 2009, 15, 3065.

42. Hazen, R. M.; Am. Mineral. 2006, 91, 1715.

43. Bonner, W. A.; Kavasmaneck, P. R.; Martin, F. S.; Flores, J. J.; Orig. Life 1975, 6, 367.

44. Hazen, R. M.; Filley, T. R.; Goodfriend, G. A.; Proc. Natl. Acad. Sci. U.S.A. 2001, $98,5487$.

45. Cody, A. M.; Cody, R. D.; J. Cryst. Growth 1991, 113, 508.

46. Orme, C. A.; Noy, A.; Wierzbicki, A.; McBride, M. T.; Grantham, M.; Teng, H. H.; Dove, P. M.; DeYoreo, J. J.; Nature 2001, 411, 775; Addadi, L.; Weiner, S.; Nature 2001, 411, 753.

47. Bonner, W. A.; Kavasmaneck, P. R.; J. Org. Chem. 1976, 41, 2225.

48. Saghatelian, A.; Yokobayashi, Y.; Soltani, K.; Ghadari, M. R.; Nature 2001, 409, 797

49. Schimidt, J. G.; Nielsen, P. E.; Orgel, L. E.; J. Am. Chem. Soc. 1997, 119, 1494.

50. Krause, E.; Bienert, M.; Schmieder, P.; Wenshuh, H.; J. Am. Chem. Soc. 2000, 122, 4865.

51. Akaike, T.; Aogaki, Y.; Onoue, S.; Biopolymers 1975, 14, 2577.

52. Hitz, T. H.; Luisi, P. L.; Orig. Life Evol. Biosph. 2004, 34, 93.

53. Bonner, W. A.; Blair, N. E.; Dirbas, F. M.; Orig. Life 1981, 11, 119; Hitz, T.; Luisi, P. L.; Helv. Chim. Acta 2003, 86, 1423.

54. Green, M. M.; Peterson, N. C.; Sato, T.; Teramoto, A.; Cook, R.; Lifson, S.; Science 1995, 268, 1860.

55. Green, M. M.; Reidy, M. P.; Johnson, R. D.; Darling, G.; O’Leary, D. J.; Wilson, G.; J. Am. Chem. Soc. 1989, 111, 6452.

56. Green, M. M.; Garetz, B. A.; Munoz, B.; Chang, H.; Hoke, S.; Cooks, R. G.; J. Am. Chem. Soc. 1995, 117, 4181; van Gestel, J.; Macromolecules 2007, 37, 3894.

57. Green, M. M.; Park, J. -W.; Sato, T.; Teramoto, A.; Lifson, S.; Selinger, R. L. B.; Selinger, J. V.; Angew. Chem., Int. Ed. 1999, 38, 3138.

58. Teramoto, A.; Prog. Polym. Sci. 2001, 26, 667; Takei, F.; Yanai, K.; Onitsuka, K.; Takahashi, S.; Chem. Eur. J. 2000, 6, 983.

59. Weissbuch, I.; Illos, R. A.; Bolbach, G.; Lahav, M.; Acc. Chem. Res. 2009, 42, 1128.

60. Wald, G.; Ann. N. Y. Acad. Sci. 1957, 69. 352.

61. Brack, A.; Spach, G.; J. Mol. Evol. 1979, 13, 35.

62. Rubinstein, I.; Eliash, R.; Bolbach, G.; Weissbuch, I.; Lahav, M.; Angew. Chem., Int. Ed. 2007, 46, 3710; Rubinstein, I.; Clodic, G.; Bolbach, G.; Weissbuch, I.; Lahav, M.; Chem. Eur. J. 2008, 14, 10999; Illos, R. A.; Bisogno, F. R.; Clodic, G.; Bolbach, G.; Weissbuch, I. Lahav, M.; J. Am. Chem. Soc. 2008, 130, 8651.

63. Jacques, J.; Collet, A.; Wilen, S. H.; Enantiomers, Racemates and Resolution, Krieger Publishing Company: Melbourne, 1991; Eliel, W. L.; 
Wilen, S. H.; Mander, L. N.; Stereochemistry of Organic Compounds, Wiley-Interscience: New York, 1994, p. 173-179.

64. Klussmann, M.; Iwamura, H.; Mathew, S. P.; Wells, D. H., Jr.; Pandya,U.; Armstrong, A.; Blachmond, D. G.; Nature 2006, 441, 621.

65. Córdova, A.; Zou, W.; Ibrahem, I.; Reyes, E.; Engqvist, M.; Liao, W.-W.; Chem. Commun. 2005, 3586.

66. Hayashi, Y.; Matsuzawa, M.; Yamagushi, J.; Yonehara, S.; Matsumoto, Y.; Shoji, M.; Hashizume, D.; Koshino, H.; Angew. Chem., Int. Ed. 2006, $45,4593$.

67. A prolina racêmica cristaliza como um composto racêmico, ou seja, uma mistura 1:1 de cocristal D- e L-prolina. Enquanto a maioria dos compostos racêmicos cristaliza desta forma, aproximadamente $15 \%$ cristalizam como conglomerados formando cristais D e L separados. Muito raramente os compostos cristalizam em formas menos definidas de soluções sólidas conhecidas como pseudorracematos.
68. Klussmann, M.; White, A. J. P.; Armstrong, A.; Blackmond, D. G.; Angew. Chem., Int. Ed. 2006, 47, 7895.

69. Klussmann, M.; Izumi, T.; White, A. J. P.; Armstrong, A.; Blackmond, D. G.; J. Am. Chem. Soc. 2007, 129, 7657.

70. Pizzarello, S.; Acc. Chem. Res. 2006, 39, 231.

71. Pizzarello, S.; Orig. Life Evol. Biosphere 2004, 34, 25.

72. Pizzarello, S.; Huang, Y.; Fuller, M.; Geochim. Cosmochim. Acta 2004, 68, 4963.

73. Levine, M.; Kenesky, C. S.; Mazori, D.; Breslow, R.; Org. Lett. 2008, 10, 2433.

74. Guijarro, A.; Yus, M.; The Origin of Chirality in the Molecules of Life, RSC Publishing: Cambridge, 2009; Wagnière, G. H.; On Chirality and the Universal Asymmetry, Wiley-VCH: New York, 2007; Meierhenrich, U.; Amino Acids and the Asymmetry of Life, Springer-Verlag: Berlin, 2008. 